\title{
PENGARUH PELATIHAN DAN PENGEMBANGAN, KEADILAN, DAN KEPEMIMPINAN TERHADAP EMPLOYEE ENGAGEMENT GENERASI MILLENNIAL DI KOTA JAKARTA
}

\author{
Lusi Savitri \\ Jurusan Ilmu Manajemen Sumberdaya Manusia, Sekolah Tinggi Manajemen PPM \\ lusi.savitri@gmail.com \\ Trengginas Wirabakti Taufiq \\ Jurusan Ilmu Manajemen Sumberdaya Manusia, Sekolah Tinggi Manajemen PPM \\ trengginaswirabakti@gmail.com \\ Dwi Idawati \\ Pembimbing pertama PPM Manajemen, Jakarta \\ dwiidawati@gmail.com \\ Julianita Kurniasari C \\ Pembimbing kedua PPM Manajemen, Jakarta \\ julianitaksc@gmail.com
}

\begin{abstract}
ABSTRAK
Penelitian ini bertujuan untuk mengetahui pengaruh pelatihan dan pengembangan, keadilan, dan kepemimpinan terhadap employee engagement generasi millennial di Kota Jakarta. Keadilan dalam penelitian ini dibagi menjadi 2, yaitu keadilan distributif dan keadilan prosedural. Sedangkan kepemimpinan dibagi menjadi kepemimpinan transaksional dan kepemimpinan transformasional. Penelitian ini dilakukan dengan menganalisis hasil kuesioner dari 391 orang karyawan generasi millennial di Kota Jakarta yang disebar dengan teknik purposive sampling. Peneltian ini menggunakan SPSS 21 sebagai alat untuk melakukan analisis regresi linear berganda. Penelitian ini menunjukan bahwa secara simultan, pelatihan dan pengembangan, keadilan, dan kepemimpinan mempengaruhi employee engagement sebesar 49,2\%. Sedangkan secara parsial, pelatihan dan pengembangan berpengaruh positif sebesar 0,465; keadilan distributif berpengaruh positif sebesar 0,177 ; keadilan prosedural berpengaruh positif sebesar 0,192; kepemimpinan transformasional berpengaruh positif sebesar 0,095; lalu kepemimpinan transaksional tidak mempengaruhi employee engagement generasi millennial di Kota Jakarta. Dari semua variabel yang diuji, pelatihan dan pengembangan menjadi variabel berpengaruh paling signifikan terhadap employee engagement generasi millennial di Kota Jakarta. Penelitian dapat memberikan masukan kepada manajer untuk dapat membuat strategi agar dapat meningkatkan employee engagement. Selain itu, saran untuk penelitian selanjutnya juga dibahas dalam penelitian ini.
\end{abstract}

Kata Kunci:

Employee Engagement, Pelatihan dan Pengembangan, Keadilan, Kepemimpinan, Generasi Millennial

\begin{abstract}
The purpose of this research is to understand the impact of training and development, justice, and leadership on employee engagement in millennials of Jakarta. Justice in this research is divided into distributive justice and procedural justice. Meanwhile, leadership is divided into transactional leadership and transformational leadership. This research is analyzing the questionnaire's result of 391 millennials employee in Jakarta using purposive sampling technique. SPSS 21 is used for statistical analysis including regression.In this research, training and development, justice, and leadership, simultaneously, effecting employee engagement as much as $49.2 \%$. Partially, training and development have 0.465 positive effect, distributive justice have 0.177 positive effect, procedural justice have 0.192 positive effect, transformational leadership have 0.095 positive effect, and transactional does not have effect on employee engagement in millennials in Jakarta. From all of the variables, training and development have the most impact on employee engagement in millennials in Jakarta. This research also provided insight for managers, so that they can formulate strategies to increase employee engagement. Suggestions for further research also discussed in this research.
\end{abstract}

Keywords:

Employee Engagement, Training and Development, Justice, Leadership, Millennials 


\section{PENDAHULUAN}

Menurut laporan dari Asian

Productivity Organization atau APO dalam

APO Productivity Databook (2017),

Indonesia berada di peringkat 11 di antara 20

negara anggota APO dalam hal produktivitas.

Data tersebut menunjukkan bahwa

produktivitas dan daya saing Indonesia masih

belum berada di puncak di antara negara

ASEAN. Meskipun demikian, menurut

Menteri Ketenagakerjaan, Hanif Dhakiri,

produktivitas Indonesia meningkat 4,62

persen dibanding tahun sebelumnya, dan di

antara provinsi yang berada di atas rata-rata

nasional, DKI Jakarta menjadi salah satunya

(Kompas.com, 2017). Penduduk yang

termasuk angkatan kerja di Jakarta berjumlah

4.861.832 jiwa di tahun 2016 (Badan Pusat

Statistik Provinsi DKI Jakarta, 2017). Tahun

2030, penduduk usia produktif di Indonesia

diperkirakan mencapai 201,8 juta jiwa atau

$68 \%$ populasi Indonesia (Badan Pusat

Statistik, 2013). Generasi millennial adalah

generasi yang lahir tahun 1980-2000, yang

saat ini berusia 18-38 tahun. Generasi ini memiliki nama lain generasi millennials atau generasi Y (Deal dan Levenson, 2016).
Tabel 1. Presentase ekspetasi lama bekerja karyawan millennial di dunia

\begin{tabular}{|c|c|c|}
\hline No & $\begin{array}{l}\text { kspetasi lama bekerja } \\
\text { aryawan millennial }\end{array}$ & Presentase \\
\hline 1 & $\leq 6$ bulan & $13 \%$ \\
\hline 2 & 6 bulan-1 tahun & $12 \%$ \\
\hline 3 & $>1$ atau 2 tahun & $19 \%$ \\
\hline 4 & $>2$ sampai 5 tahun & $22 \%$ \\
\hline 5 & $>$ 5 sampai 10 tahun & $11 \%$ \\
\hline 6 & $>10$ tahun & $5 \%$ \\
\hline 7 & Tidak pernah pindah & $11 \%$ \\
\hline 8 & Tidak tahu & $8 \%$ \\
\hline
\end{tabular}

Sumber: The 2016 Deloitte Millennial Survei, 2016

Menurut Badan Pusat Statistik Jakarta (2017), jumlah penduduk Jakarta yang bekerja dari usia 15-39 tahun sebesar 2.568.423 jiwa atau 58.66\%. Menurut penelitian The 2016 Deloitte Millennial Survei (2016), 2 dari 3 orang karyawan millennial beharap bisa pindah dari pekerjaan di tahun 2020. Tabel 1 menunjukkan persentase ekspektasi lama bekerja karyawan millennial di dunia.

Dari tabel di atas dapat disimpulkan bahwa jumlah karyawan millennial yang akan berpindah tempat kerja dengan lama bekerja $\leq 6$ bulan sampai 5 tahun sebesar 66\%. Di Indonesia, karyawan millennial yang ingin berpindah pekerjaan setelah kurang dari 5 tahun bekerja, presentasenya sebesar $62 \%$. Menurut Ali dan Purwandi (2017), anggapan generasi millennial ialah semakin sering pindah tempat kerja berarti termasuk orang yang "laku" di perusahaan. 
Selain itu, generasi millennial lebih nyaman jika bekerja pada lingkungan yang mampu memfasilitasi kebutuhan mereka.

Hal tersebut membuat perusahaan rugi karena harus mengeluarkan biaya untuk proses rekrutmen dan seleksi. Perusahaan juga dapat kehilangan orang yang berkompeten. Turnover merupakan salah satu tantangan mengenai tenaga kerja yang paling mahal dan sulit (Surji, 2013). Perusahaan saat ini harus memperhatikan sumber daya manusia yang ada di dalam organisasi agar tercipta employee engagement yang berdampak pada organisasi. Employee engagement merupakan keterikatan karyawan terhadap organisasi dan pekerjaannya (Saks, 2006).

Apabila perusahaan memperhatikan engagement, maka akan memiliki dampak positif. Menurut Rothwell et. al. (2014), keuntungan sebuah perusahaan memperhatikan engagement karyawan ialah tidak banyak karyawan yang keluar, organisasi memiliki kinerja yang lebih baik, dan perusahaan mendapat profit yang lebih tinggi. Oleh karena itu, maka peneliti ingin mengambil topik mengenai faktor-faktor yang mempengaruhi employee engagement generasi millennial di Kota Jakarta.

Terdapat beberapa penelitian mengenai faktor yang mempengaruhi employee engagement. Saks (2006), melakukan penelitian mengenai Antecedents and Consequence Employee engagement. Hasilnya, anteseden dari employee engagement ialah job characteristic dan keadilan prosedural. Penelitian ini menyarankan agar karakteristik dari anteseden ditambah yaitu pelatihan. Sattar, Ahmad, dan Hussein (2015) melakukan penelitian mengenai antecedents and consequences employee engagemenent di Pakistan. Hasilnya adalah training, reward, dan empowerment mempengaruhi employee engagement karyawan bank di Pakistan. Kemudian, hasil penelitian dari Lai et. al., (2015), adalah training and development dan coworker support mempengaruhi employee engagement.

Hasil penelitian oleh Saragih, Widodo, dan Prasetyo (2016), ada 4 variabel yang berpengaruh terhadap komitmen organisasi generasi millennial di Indonesia yaitu benefit, promosi, fleksibilitas kerja, dan lokasi kerja. Kemudian, Li, Castano, dan Lin (2018), melakukan penelitian dengan variabel bebas kepemimpinan transaksional, kepemimpinan transformasional, dan psychological capital. 
Hasilnya adalah kepemimpinan

transaksional,

kepemimpinan

transformasional, dan psychological capital mempengaruhi employee engagement. Menurut Lubis (2012), kepemimpinan transaksional mempengaruhi employee engagement. Menurut penelitian Alvi dan Abassi (2012), keadilan distributif berpengaruh terhadap employee engagement di Pakistan. Cara agar millennial bertahan di tempat kerja adalah dengan memberikan waktu kerja yang fleksibel, tempat bekerja yang fleksibel (remote working) dan memberikan fasilitas yang dibutuhkan (Deloitte, 2016). Dari penelitian di atas, faktor yang mempengaruhi employee engagement yang belum banyak diteliti di Jakarta terdiri dari fasilitas, desain ruangan kerja, waktu kerja yang fleksibel, tempat kerja yang fleksibel, pelatihan dan pengembangan, kepemimpinan transaksional, kepemimpinan transformasional, keadilan prosedural, dan keadilan distributif. Sembilan faktor tersebut kemudian dijadikan survei preliminary.

Survei ini menggunakan kuesioner sebagai instrumen penelitian preliminary. Kuesioner disebar kepada 32 karyawan millennial yang bekerja di Jakarta. Menurut

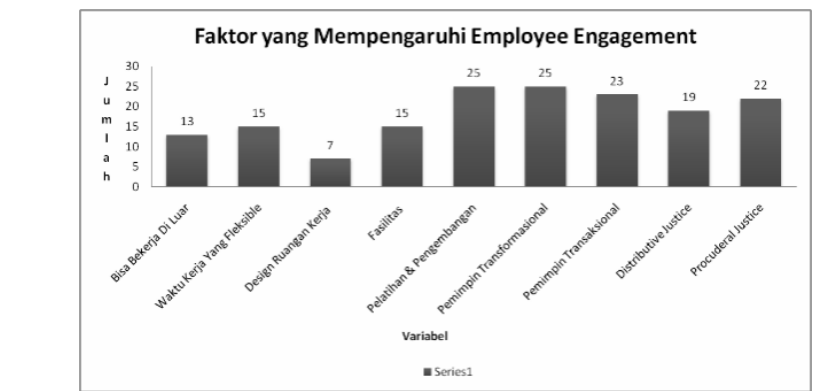

Devore dan Peck (1990), survei awal dapat

\section{Gambar 1. Survei preliminary karyawan millennial}

dilakukan dengan responden minimal 30 orang. Setiap responden harus memilih 5 dari 9 faktor yang menjadi faktor penting untuk bertahan di tempat kerjanya. Hasil dari survei tersebut terdapat pada gambar 1 .

Berdasarkan hasil survei di atas, maka dipilihlah pelatihan dan pengembangan, keadilan distributif, keadilan prosedural, kepemimpinan transaksional, dan kepemimpinan transformasional untuk menjadi variabel penelitian. Selain itu, penelitian ini ingin dilakukan karena masih sedikit penelitian yang membahas mengenai faktor-faktor yang mempengaruhi employee engagement menggunakan variabel pelatihan dan pengembangan, keadilan distributif, keadilan prosedural, kepemimpinan transaksional, dan kepemimpinan transformasional kepada generasi millennial di Jakarta.

Penelitian ini bertujuan untuk mengetahui: 
(1) Pengaruh pelatihan dan pengembangan, kepemimpinan, dan keadilan terhadap employee engagement generasi millennial di Kota Jakarta secara parsial; (2) Pengaruh pelatihan dan pengembangan, kepemimpinan, dan keadilan terhadap employee engagement generasi millennial di Kota Jakarta secara simultan; (3) Variabel yang paling signifikan berpengaruh kepada employee engagement generasi millennial di Kota Jakarta di antara pelatihan dan pengembangan, kepemimpinan, dan keadilan.

\section{TINJAUAN TEORI DAN}

\section{PENGEMBANGAN HIPOTESIS}

\section{Generasi Millennial}

Millennial merupakan generasi yang lahir tahun 1980-2000. Nama lain millennial adalah Echo Boomers, Gen Y, dan Net Gen. Milennial tumbuh saat teknologi berkembang daripada generasi sebelumnya (Deal dan Levenson, 2016).

Generasi Milennial atau yang disebut Gen Y adalah generasi yang lahir tahun 1980-2000. Jumlah generasi ini ada 92 juta orang. Generasi ini hidup saat adanya teknologi yang canggih seperti penggunaan sosial media, pesan teks, penggunaan handphone, dan memiliki penekanan yang kuat terhadap tanggung jawab sosial (Espinoza dan Ukleja, 2016).

\section{Employee Engagement}

Keterikatan kerja merupakan lawan dari kejenuhan (burnout) (Schaufeli, Salanova, Roma, dan Bakker, 2002). Keterikatan kerja terdiri dari vigor (semangat), dedication (dedikasi), dan absorption (Schaufeli, Bakker, Salanova, 2006). Employee engagement ialah keterlibatan individu, perasaan puas, dan antusias terhadap pekerjaan (Robbins dan Judges, 2015).

\section{Pelatihan dan Pengembangan}

Pelatihan adalah usaha yang terencana oleh perusahaan untuk memfasilitasi pembelajaran kompetensi, pengetahuan, keterampilan, dan sikap yang berhubungan dengan pekerjaan. Sedangkan pengembangan adalah pelatihan dan edukasi formal, pengalaman kerja, hubungan, dan penilaian kepribadian, keterampilan, dan kemampuan untuk membantu karyawan mempersiapkan diri untuk pekerjaan atau posisi di masa depan (Noe, 2017).

Menurut Bohlander dan Snell (2013), 
seseorang banyak menghabiskan waktu untuk bekerja, sehingga mereka harus membuat perencanaan pengembangan karir.

\section{Keadilan Distributif}

Keadilan distributif membahas mengenai persepsi karyawan mengenai keadilan dari hasil-hasil keputusan dari perusahaan (Colquitt, 2001). Keadilan distributif adalah keadilan yang dirasakan oleh karyawan atas imbalan yang dialokasikan setiap individu (Robbins dan Judge, 2015).

\section{Keadilan Prosedural}

Keadilan prosedural adalah isu keadilan yang berhubungan dengan metode, mekanisme, dan proses yang digunakan untuk menentukan suatu hasil (Rupp dan Cropanzano, 2002). Selain itu, keadilan prosedural juga berarti persepsi keadilan tentang proses yang digunakan untuk menentukan pembagian imbalan (Robbins \& Judge, 2015).

\section{Kepemimpinan Transaksional}

Pada kepemimpinan transaksional, pemimpin bergantung pada pemberian penghargaan. Penghargaan yang diberikan bergantung kepada apa yang bawahan selesaikan (Bertocci, 2009). Pemimpin memberikan target dan reward berdasarkan pada kinerja bawahan (Bass dan Avolio, 1992).

\section{Kepemimpinan Transformasional}

Pada kepemimpinan transformasional, pemimpin memiliki karakteristik idealized influenced, inspirational motivation, intellectual stimulation, dan individualized consideration (Bass dan Avolio, 1992). Para pemimpin transformasional menginspirasi para pengikut untuk lebih mementingkan kepentingan organisasi daripada kepentingan pribadi. Pemimpin transformasional merupakan kepemimpinan yang sangat efektif dan memiliki pengaruh yang luar biasa terhadap para pengikutnya (Robbins dan Judge, 2015).

Berdasarkan penjelasan di atas, hipotesisnya ialah sebagai berikut:

H1: Pelatihan dan pengembangan mempengaruhi employee engagement secara positif

H2: Keadilan distributif mempengaruhi employee engagement secara positif

H3: Keadilan prosedural mempengaruhi employee engagement secara positif 


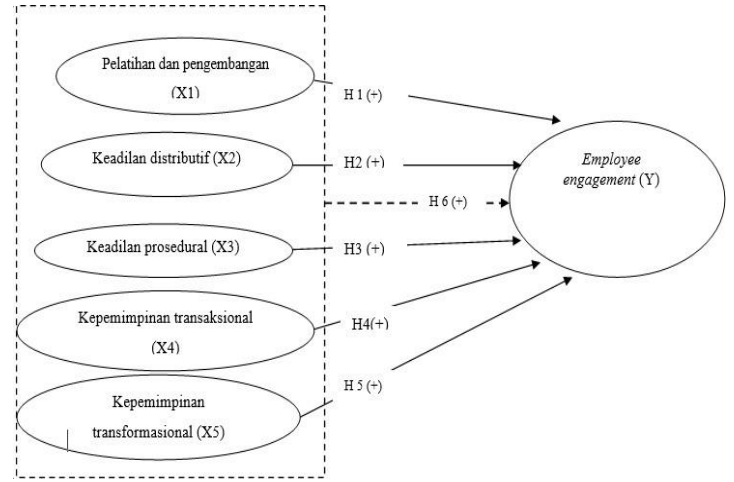

Gambar 2. Model Penelitian

H4: Kepemimpinan transaksional mempengaruhi employee engagement secara positif

H5: Kepemimpinan transformasional mempengaruhi employee engagement secara positif

H6: Pelatihan dan pengembangan, keadilan distributif, keadilan prosedural, kepemimpinan transaksional, dan kepemimpinan transformasional secara simultan berpengaruh terhadap employee engagement.

Berdasarkan penjelasan di atas, maka model penelitian terdapat pada gambar 2 .

\section{METODE RISET}

Jenis penelitian yang digunakan ialah penelitian kuantitatif dengan pengujian hipotesis. Data primer dalam penelitian ini merupakan data yang didapat dari hasil survei kepada responden. Lalu, data sekunder merupakan data dari penelitian sebelumnya, data yang didapat dari buku literatur, jurnal, karya ilmiah, laporan ilmiah, dan berita online. Menurut BPS, pada tahun 2017 terdapat sekitar 2.568.423 penduduk Jakarta di kalangan umur 15-39 tahun yang bekerja. Populasi tersebut diambil karena range umur tersebut paling mendekati range umur millennial yaitu 18-38 tahun.

Teknik sampling yang digunakan menggunakan purposive sampling. Penentuan jumlah sampel berdasarkan Tabel Krejcie dan Morgan (1970). Apabila populasi berjumlah lebih dari 1.000.000 dengan tingkat kepercayaan $95 \%$ dan alpha 0,05 , maka sampel yang diambil minimal 384 orang. Kriteria sampel yang diambil adalah: (1) Karyawan yang lahir tahun 19802000; (2) Karyawan yang bekerja di perusahaan; (3) Karyawan yang bekerja di Kota Jakarta.

Sampling framework dengan cara memberikan kuesioner kepada mahasiswa program Sarjana Manajemen Bisnis Pro, Magister Manajemen Eksekutif Muda, mahasiswa program Magister mahasiswa Eksekutif, dan Alumni PPM yang berjumlah total 701 orang. Data yang kembali sebesar 483 responden, 391 responden memenuhi kriteria dan 92 responden tidak memenuhi kriteria. 
Instrumen penelitian yang digunakan ialah kuesioner. Skala yang digunakan menggunakan skala Likert. Variabel bergantung berupa employee engagement menggunakan kuesioner dari Schaufeli, Bakker, dan Salanova (2006), Kepemimpinan transaksional dan transformasional menggunakan kuesioner dari Bass dan Avolio (1992), keadilan distributif berasal dari Colquitt (2001). Kuesioner keadilan prosedural dari Rupp dan Cropanzano (2002), dan kuesioner pelatihan dan pengembangan dari Manuel (2014). Definisi Operasional setiap variabel tertera pada tabel 2 .

Uji validitas dan reliabilitas kuesioner dilakukan kepada 35 responden. Kuesioner tersebut terdapat 1 item yang tidak valid, yaitu pernyataan pada variabel pelatihan dan pengembangan (Pelatihan dan pengembangan membantu saya melakukan pekerjaan saya dengan lebih baik) yang memiliki nilai $r$ hitung 0,294 . Nilai ini lebih kecil dari pada $r$ tabel $(r=0,3338)$. Semua item pada kuesioner reliabel. Karena nilai alpha lebih besar dari 0,6. Metode pengumpulan data dalam penelitian ini ialah survey menggunakan kuesioner melalui Google form. Cara melakukan pengolahan data yaitu,
Tabel 2. Definisi operasional variabel

\begin{tabular}{|l|l|}
\hline Variabel & Desinisi Operasional \\
Engloyee & $\begin{array}{l}\text { Keterikatan kerja terdiri dari } \\
\text { vigor (semangat), dedication } \\
\text { (dedikasi), dan absorption } \\
\text { (Schaufeli, Bakker, Salanova, } \\
\text { 2006) }\end{array}$ \\
\hline $\begin{array}{l}\text { Pelatihan dan } \\
\text { Pengembangan }\end{array}$ & $\begin{array}{l}\text { Suatu usaha yang dirancang } \\
\text { secara berkelanjutan untuk } \\
\text { meningkatkan kemampuan } \\
\text { karyawan untuk pekerjaan atau } \\
\text { posisi saat ini dan masa depan } \\
\text { (Noe, 2017) }\end{array}$ \\
\hline $\begin{array}{l}\text { Keadilan } \\
\text { Distributif }\end{array}$ & $\begin{array}{l}\text { Persepsi karyawan mengenai } \\
\text { keadilan dari hasil-hasil } \\
\text { keputusan dari perusahaan } \\
\text { (Colquitt, 2001). }\end{array}$ \\
\hline $\begin{array}{l}\text { Keadilan } \\
\text { Prosedural }\end{array}$ & $\begin{array}{l}\text { Keadilan didalam kebijakan } \\
\text { dan prosedur di organisasi (Rupp } \\
\text { \& Cropanzano, 2002) }\end{array}$ \\
\hline $\begin{array}{l}\text { Kepemimpinan } \\
\text { Transaksional }\end{array}$ & $\begin{array}{l}\text { Pemimpin memberikan target dan } \\
\text { reward berdasarkan pada } \\
\text { kinerja bawahan (Bass dan } \\
\text { Avolio, 1992). }\end{array}$ \\
\hline $\begin{array}{l}\text { Kepemimpinan } \\
\text { Transformasional }\end{array}$ & $\begin{array}{l}\text { Pemimpin yang memiliki } \\
\text { karakteristik idealized } \\
\text { influenced, inspirational } \\
\text { motivation, intellectual } \\
\text { stimulation, dan individualized } \\
\text { consideration (Bass dan } \\
\text { Avolio, 1992) }\end{array}$ \\
\hline
\end{tabular}

data dari kuesioner google form diunduh dalam bentuk excel. Kemudian, menghapus data dari sampel yang tidak memenuhi kriteria. Analisis data dilakukan dengan program SPSS 21 (Statistical Product and Service Solution). Tahap analisis data yaitu melakukan uji validitas dan uji reliabilitas terhadap 35 responden, melakukan uji validitas dan reliabilitas terhadap 391 sampel, uji asumsi klasik (uji normalitas, uji heteroskedastisitas, uji multikolinearitas, dan uji autokorelasi), uji hipotesis (uji F, uji t), uji eterminsi dan regresi linear berganda. 
Pengaruh Pelatihan dan Pengembangan.... (Lusi Savitri, Trengginas WT, Dwi Idawati \& Julianita KC)

\section{PEMBAHASAN}

Setelah kuesioner disebar, dilakukan uji asumsi klasik, yaitu uji normalitas, uji heteroskedastisitas, dan uji multikolinearitas. Hasil penelitian ini lolos uji asumsi klasik. Lalu pada uji korelasi dan determinasi hasilnya adalah $\mathrm{R}=0,702$ dan $\mathrm{R}^{2}=0,492$. Hal tersebut menandakan bahwa variabel independen dalam penelitian ini secara kuat mempengaruhi variabel dependen, dan variabel independen mempengaruhi variabel dependen sebesar $49,2 \%$, dan sisanya dipengaruhi oleh faktor lain.

\section{Pelatihan dan Pengembangan}

Variabel pelatihan dan pengembangan memiliki nilai siginifikansi sebesar 0,000 , nilai tersebut lebih kecil dari 0,05. Selain itu t hitung variabel pelatihan dan pengembangan adalah 9,202, yang mana nilai tersebut lebih besar dari t tabel yaitu 1,996. Maka dapat disimpulkan bahwa variabel pelatihan dan pengembangan dinyatakan signifikan mempengaruhi employee engagement secara positif, yang berarti semakin banyak pelatihan dan pengembangan, maka employee engagement akan semakin besar pula. Selain itu, dalam penelitian ini pelatihan dan pengembangan menjadi variabel yang paling berpengaruh terhadap employee engagement. Hal ini sesuai dengan penelitian yang dilakukan oleh Lai, et. al. (2015), di mana pelatihan dan pengembangan berpengaruh terhadap employee engagement pada industri perhotelan. Karyawan butuh lebih banyak pelatihan dan pengembangan. Manager HR harus menciptakan training and development system. Tenaga kerja merupakan asset yang penting. Menurut Sattar, Ahmad, dan Hasan (2015), training mempengaruhi employee engagement secara positif. Perusahaan harus fokus terhadap training dan empowerment karyawan.

\section{Keadilan Distributif}

Variabel keadilan distributif memiliki nilai siginifikansi sebesar 0,015 , nilai tersebut lebih kecil dari alpha $(0,05)$. Selain itu thitung variabel keadilan distributif adalah 2,446, yang mana nilai tersebut lebih besar dari t tabel yaitu 1,996. Maka dapat disimpulkan bahwa variabel keadilan distributif dinyatakan signifikan untuk mempengaruhi employee engagement secara positif.. Hal ini sesuai dengan penelitian Biswas, Varma, dan Ramaswari (2013), bahwa keadilan distributif berpengaruh terhadap employee engagement di India. Untuk memastikan karyawan terikat secara optimal, manajer dan eksekutif harus mengambil langkah yang sesuai 
untuk memastikan agar keadilan distributif terlaksana melalui pemberian kompensasi yang adil dan menerapkan norma kerja yang adil. Selain itu, Ghosh, Rai, dan Sinha (2014), bahwa keadilan distributif berpengaruh terhadap employee engagement di sektor bank publik India. Karyawan berekspetasi organisasi memberikan penghargaan atas usahanya. Distribusi outcome (pay, promotion) harus didesain secara adil untuk meningkatkan persepsi keadilan karyawan.

\section{Keadilan Prosedural}

Variabel keadilan prosedural memiliki nilai siginifikansi sebesar 0,020 , nilai tersebut lebih kecil dari 0,05. Selain itu t hitung variabel keadilan prosedural adalah 2,327, yang mana nilai tersebut lebih besar dari $\mathrm{t}$ tabel yaitu 1,996. Maka dapat disimpulkan bahwa variabel keadilan prosedural dinyatakan signifikan untuk mempengaruhi employee engagement secara positif, yang berarti semakin kuat keadilan prosedural, maka employee engagement akan semakin kuat pula. Hal ini sesuai dengan penelitian yang dilakukan oleh Biswas, Varma, dan Ramaswari (2013), bahwa keadilan prosedural berpengaruh terhadap employee engagement di perusahaan jasa dan manufaktur di India. Menurut Yulianti (2016), menyatakan bahwa keadilan prosedural berpengaruh kepada employee engagement. Keadilan pemberian tugas serta mengimplementasikan kebijakan secara konsisten menyebabkan karyawan merasa penuh energi, larut dalam pekerjaan, tidak terasa waktu berakhir, dan merasa menikmati pekerjaan. Menurut Ozer, Ogurlouglu, dan Saygili (2017), keadilan prosedural mempengaruhi employee enagegement.

\section{Kepemimpinan Transaksional}

Variabel kepemimpinan transaksional memiliki nilai siginifikansi sebesar 0,857 , nilai tersebut lebih besar dari 0,05 . Selain itu t hitung variabel kepemimpinan transaksional adalah 0,180, yang mana nilai tersebut lebih kecil dari $\mathrm{t}$ tabel yaitu 1,996. Maka dapat disimpulkan bahwa variabel kepemimpinan transaksional dinyatakan tidak signifikan untuk mempengaruhi employee engagement. Hasil penelitian ini sejalan dengan penelitian Colbert (2012), bahwa kepemimpinan transaksional tidak mempengaruhi employee engagement di perusahaan manufaktur United States. Karyawan menyukai pemimpin yang menunjukkan empati, mengembangkan karyawan, dan mengikutsertakan karyawan dalam membuat 
keputusan. Hasil penelitian ini berbeda dengan penelitian yang dilakukan oleh Lubis (2012), yang menyatakan bahwa kepemimpinan transaksional berpengaruh positif kepada employee engagement.

\section{Kepemimpinan Transformasional}

Variabel

kepemimpinan

transformasional memiliki nilai siginifikansi sebesar 0,005 , nilai tersebut lebih kecil dari 0,05. Selain itu $\mathrm{t}$ hitung variabel kepemimpinan transformasional adalah 2,851, yang mana nilai tersebut lebih besar dari t tabel yaitu 1,996. Maka dapat disimpulkan bahwa variabel kepemimpinan transformasional dinyatakan signifikan untuk mempengaruhi employee engagement secara positif. Hal ini sesuai dengan penelitian yang dilakukan oleh Muarniata (2012), yang menyatakan bahwa kepemimpinan berpengaruh positif pada employee engagement. Dengan menerapkan gaya kepemimpinan transformasional, dapat mendorong pegawainya lebih menikmati dan larut dalam pekerjaan. Menurut Zhang, Avery, Bergsteiner, dan More (2014), menyatakan di Sidney kepemimpinan transformasional juga memiliki pengaruh positif terhadap employee engagement.
Tabel 3. Hasil Uji Simultan

\begin{tabular}{|c|c|c|c|c|c|c|}
\hline \multicolumn{2}{|c|}{ Model } & \multirow{2}{*}{ 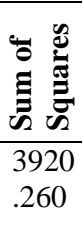 } & \multirow{2}{*}{$\begin{array}{l}\mathbf{d} \\
\mathbf{f} \\
5\end{array}$} & \multirow{2}{*}{ 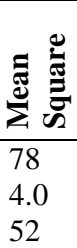 } & \multirow{2}{*}{$\begin{array}{l}\mathbf{F} \\
\\
74 . \\
67 \\
2\end{array}$} & \multirow{2}{*}{$\begin{array}{l}\text { Si } \\
\text { g. } \\
.00 \\
0^{\mathrm{b}}\end{array}$} \\
\hline 1 & Regression & & & & & \\
\hline & Residual & $\begin{array}{c}4042 \\
.502\end{array}$ & $\begin{array}{l}3 \\
8 \\
5\end{array}$ & $\begin{array}{l}10 . \\
50 \\
0\end{array}$ & & \\
\hline & Total & $\begin{array}{l}7962 \\
.762\end{array}$ & $\begin{array}{l}3 \\
9 \\
0\end{array}$ & & & \\
\hline
\end{tabular}

a. Dependent variable: EE

b. Predictors: (constant), TRANF, PEL, DI, SAK, PRO

\section{Uji F atau Simultan}

Pada penelitian ini juga dilakukan uji $\mathrm{F}$ atau simultan untuk melihat apakah variabel independen secara simultan mempengaruhi variabel dependen.

Hipotesisnya ialah sebagai berikut.

$\mathrm{H}_{0}$ : Pelatihan dan pengembangan, keadilan distributif, keadilan prosedural, kepemimpinan transaksional, kepemimpinan transformasional secara simultan tidak mempengaruhi employee engagement.

$\mathrm{H}_{1}$ : Pelatihan dan pengembangan, keadilan distributif, keadilan prosedural, kepemimpinan transaksional, kepemimpinan transformasional secara simultan mempengaruhi employee engagement.

Dari Tabel 3, $\mathrm{H}_{0}$ ditolak karena $\mathrm{F}_{\text {hit }}$ $(73,219)>F_{\text {tabel }}(2,237)$ dan Sig. $(0,000)<\alpha$ $(0,05)$. Maka dapat disimpulkan bahwa pelatihan dan pengembangan, keadilan distributif, keadilan 
prosedural, kepemimpinan transaksional, kepemimpinan transformasional mempengaruhi employee engagement secara simultan.

\section{Model Regresi}

Model regresi linear berganda ialah sebagai berikut:

$$
Y=9,292+0,465 X_{1}+0,177 X_{2}+
$$

$0,192 X_{3}+0,011 X_{4}+0,095 X_{5}$

Dimana:

\section{Y: Employee Engagement}

$\mathrm{X} 1$ : Pelatihan dan pengembangan

X2: Keadilan distributif

X3: Keadilan prosedural

X4: Kepemimpinan transaksional

X5: Kepemimpinan transformasional

Dari hasil analisis penelitian di atas, maka dapat disimpulkan bahwa variabel pelatihan dan pengembangan, keadilan distributif, keadilan prosedural, kepemimpinan transaksional dan kepemimpinan transformasional secara simultan mempengaruhi employee engagement. Jika terjadi kenaikan pada variabel tersebut, maka akan mempengaruhi nilai employee engagement.

Pelatihan dan pengembangan mempengaruhi employee engagement sebesar 0,465, yang berarti jika pelatihan dan pengembangan naik 1 poin, maka employee engagement akan naik sebesar 0,465 Poin. Keadilan distributif mempengaruhi employee engagement sebesar 0,177, yang berarti jika keadilan distributif naik 1 poin, maka employee engagement akan naik sebesar 0,177 Poin. Keadilan prosedural mempengaruhi employee engagement sebesar 0,192, yang berarti jika keadilan prosedural naik 1 poin, maka employee engagement akan naik sebesar 0,192 Poin. Kepemimpinan transformasional mempengaruhi employee engagement sebesar 0,095, yang berarti jika kepemimpinan transformasional naik 1 poin, maka employee engagement akan naik sebesar 0,095 poin.

\section{KESIMPULAN DAN SARAN}

\section{Kesimpulan}

Pelatihan dan pengembangan berpengaruh positif terhadap employee engagement sebesar 0.465 . Keadilan distributif berpengaruh positif terhadap employee engagement sebesar 0.177. Keadilan prosedural berpengaruh positif terhadap employee engagement sebesar 0.192. Kepemimpinan transformasional berpengaruh positif terhadap employee engagement sebesar 
0.095. Kepemimpinan transaksional tidak berpengaruh terhadap employee engagement. Secara simultan, berdasarkan uji regresi, variabel pelatihan dan pengembangan, keadilan distributif, keadilan prosedural, kepemimpinan transaksional dan kepemimpinan transformasional mempunyai nilai $\mathrm{R}=0.702$, hal tersebut membuktikan bahwa variabel independen mempengaruhi employee engagement generasi millennial di Kota Jakarta secara kuat. Variabel independen berkontribusi terhadap employee engagement sebesar 49,2\%, dan selebihnya dipengaruhi faktor lain.

Selain itu, berdasarkan hasil penelitian, dapat diketahui bahwa pelatihan dan pengembangan menjadi variabel yang paling mempengaruhi employee engagement generasi millennial di Kota Jakarta dibandingkan variabel lain.

\section{Saran}

Hasil penelitian ini tidak sepenuhnya sesuai dengan penelitian terdahulu. Karena variabel dalam penelitian ini masih terbatas. Terdapat variabel lain yang belum tergali secara mendalam. Maka sebaiknya untuk penelitian selanjutnya menambahkan variabel lain seperti jenis kelamin dan waktu lamanya bekerja responden. Selain itu, sebaiknya penelitian dilakukan di industri yang spesifik, misalnya di organisasi non-profit, perusahaan start-up, industri e-commerce, dan lain-lain. Kemudian, variabel pelatihan dan pengembangan sebaiknya dipisah, karena pada dasarnya pelatihan dan pengembangan, masingmasing memiliki definisi yang berbeda.

\section{Implikasi Teoritis}

Pada penelitian ini, responden yang diteliti adalah karyawan generasi millennial yang bekerja di perusahaan di Jakarta. Akan tetapi, penelitian ini tidak melihat lama waktu bekerja dan jenis kelamin. Hasil dari penelitian ini adalah variabel pelatihan dan pengembangan berpengaruh terhadap employee engagement. Hal ini sesuai dengan penelitian Lai, et.al., (2015) yang meneliti mengenai employee engagement kepada 400 responden di industri hotel bintang 5 di Malaysia. Rentang umur responden yang diteliti adalah 20 sampai dengan lebih dari 50 tahun dengan mayoritas responden berusia 20-29 tahun. Sedangkan pengalaman kerja para responden memiliki rentang dari di bawah 1 tahun sampai diatas 4 tahun, dengan mayoritas responden memiliki pengalaman kerja di bawah 2 tahun. Variabel bebas yang digunakan ialah training and development dan coworker support. 
Kedua variabel tersebut berpengaruh terhadap employee engagement. Persamaan dalam hasil penelitian ini mungkin terjadi karena penelitian Lai, et.al.,(2015) memiliki responden mayoritas generasi millennial. Pada penelitian Saks (2006), keadilan distributif tidak mempengaruhi employee engagement di Kanada. Penelitian Saks menggunakan variabel bebas job characteristics, reward and recognition, distributive justice, procedural justice, perceived organizational support dan perceived supervisor support. Variabel consequences dari employee engagement adalah job satisfaction, organizational commitment, intention to quit, organizational citizenship behavior. Pada penelitian Saks (2006), anteseden yang mempengaruhi employee engagement adalah job characteristic dan procedural justice. Lalu, employee engagement berpengaruh terhadap job satisfaction, intention to quit, dan organizational citizenship behavior.

Pada penelitian Alvi dan Abassi (2012), keadilan distributif berpengaruh terhadap employee engagement di sektor bank Pakistan kepada 312 responden. Penelitian tersebut menggunakan 3 variabel, yaitu keadilan distributif, keadilan prosedural, dan keadilan interaksional. Hasilnya adalah keadilan distributif dan keadilan interaksional berpengaruh positif terhadap employee engagement. Sedangkan keadilan prosedural, tidak berpengaruh terhadap employee engagement. Hal tersebut berbeda dengan penemuan dalam penelitian ini bahwa keadilan prosedural mempunyai pengaruh positif terhadap employee engagement.

Menurut penelitian Ozer, Ugurlouglu, dan Saygili (2017), keadilan distributif dan prosedural berpengaruh positif terhadap employee engagement pada 414 pegawai rumah sakit di Turki. Variabel independen yang digunakan ialah keadilan distributif, keadilan prosedural, dan keadilan interaksional dengan variabel bebas employee engagement. Hal senada juga ditemukan dalam penelitian ini bahwa keadilan distributif dan prosedural berpengaruh positif kepada employee engagement.

Dalam penelitian ini kepemimpinan transformasional berpengaruh positif terhadap employee engagement. Hal senada juga terdapat dalam penelitian Menurut Zhang, Avery, Bergsteiner, dan More (2014), menyatakan di Sidney kepemimpinan transformasional juga 
memiliki pengaruh positif terhadap employee engagement. Mayoritas responden berumur 25-34, yang mana rentang umur tersebut adalah generasi millennial. Kemudian, menurut Li, Castano, dan Lin (2018) melakukan penelitian mengenai hubungan kepemimpinan dengan employee engagement. Penelitian ini menggunakan sampel karyawan yang bekerja tidak lebih dari 1 tahun di Provinsi China. Penelitian ini menggunakan variabel independen kepemimpinan transaksional dan kepemimpinan transformasional. Hasilnya adalah kepemimpinan transaksional mempengaruhi employee engagement, yang mana hal tersebut berbeda dengan dengan hasil temuan dalam penelitian ini yang tidak membatasi lama waktu bekerja, bahwa kepemimpinan transaksional tidak mempengaruhi employee engagement generasi millennial di Jakarta. Akan tetapi, hal ini sejalan dengan penelitian Colbert (2012), bahwa kepemimpinan transaksional tidak mempengaruhi employee engagement di perusahaan manufaktur United States. Pada penelitian ini variabel independennya adalah kepemimpinan transaksional, $\quad$ kepemimpinan transformasional dan kepemimpinan autentik.
Hasilnya adalah kepemimpinan transaksional tidak mempengaruhi employee engagement. Variabel kepemimpinan transformasional dan kepemimpinan autentik juga tidak mempengaruhi employee engagement.

\section{Implikasi Manajerial}

Berdasarkan hasil penelitian ini terdapat beberapa implikasi manajerial. Para manajer atau atasan sebaiknya mengerti tentang adanya pengaruh positif dari pelatihan dan pengembangan, keadilan distributif, keadilan prosedural, dan kepemimpinan transformasional terhadap employee engagement. Pada penelitian ini, pelatihan dan pengembangan menjadi variabel yang paling berpengaruh terhadap employee engagement. Dengan kata lain, pelatihan dan pengembangan bisa menjadi salah satu prioritas manajer atau atasan. Pelatihan dan pengembangan juga sebaiknya sesuai dengan strategi perusahaan agar bisa meningkatkan kinerja karyawan. Millennial berharap belajar keterampilan baru, dibimbing bagaimana cara menyelesaikan masalah, dan bagaimana cara mendapatkan informasi. Sehingga, atasan harus memberikan bawahan keterampilan baru, bagaimana cara menyelesaikan masalah, dan bagaimana cara mendapatkan informasi (Zemke, Raines, dan Filipczak, 2013). 
Millennial sangat menginginkan

kesempatan untuk mengembangkan dirinya, maka perusahaan harus mengadakan program pengembangan. Manajer HR harus membuat program yang memberikan kesempatan belajar. Pelatihan dan pengembangan yang dilakukan, harus sesuai dengan pekerjaannya (Deal dan Levenson, 2016).

Dalam penelitian ini keadilan distributif dan prosedural mempengaruhi employee engagement. Maka, sebaiknya atasan lebih terbuka terhadap prosedur dan peraturan yang digunakan untuk menentukan imbalan. Selain itu karyawan juga diikut sertakan dalam pembuatan prosedur agar diberikan kesempatan untuk memberikan opininya dalam prosedur yang dibuat atau sedang digunakan. Atasan juga harus konsisten dalam membuat keputusan mengenai imbalan. Selain itu, bawahan juga sebaiknya diberikan imbalan, baik dalam bentuk financial maupun non financial, berdasarkan standar perusahaan. Pemberian gaji dan promosi juga harus sesuai dengan prosedur dan peraturan yang berlaku. Atasan juga harus berani melakukan inovasi terhadap prosedur atau peraturan yang dianggap tidak adil oleh dirinya dan bawahannya (Robbins dan Judge ,2015).

Millennial ingin melakukan diskusi mengenai peraturan yang dibuat perusahaan. Atasan harus menuliskan target di atas kertas untuk membantu millennial tetap fokus dan bertanggung jawab terhadap atasan. Saat pemberian feedback, yang harus dilakukan atasan kepada millennial adalah mengadakan meeting one on one, kemudian diawali dengan memberikan feedback yang positif. Atasan harus memberikan feedback yang konstan untuk karir yang lebih baik (Hess, 2012).

Millennial membutuhkan feedback yang spesifik, konstruktif, dan konstan. Millennial ingin mengetahui apakah kinerjanya meningkat atau tidak. Mentor atau atasan harus ahli dalam memberikan feedback. Cara memberikan feedback ialah bertemu secara private, berbicara secara langsung atau face to face, menemukan jalan untuk perbaikan ke depan, dan memutuskan apa yang harus dimulai (Zemke, Raines, dan Filipczak, 2013).

Hubungan antara karyawan millennial dengan manajer sama pentingnya dengan hubungan antara millennial dengan teman kerjanya. Perusahaan harus mengadakan program mentoring baik dalam suasana formal maupun non formal. Millennial menginginkan 
Pengaruh Pelatihan dan Pengembangan.... (Lusi Savitri, Trengginas WT, Dwi Idawati \& Julianita KC)

coaching yang relevan dengan pekerjaan saat ini dan pekerjaan yang akan datang. Millennial ingin tahu bagaimana caranya menjadi karyawan yang sukses (Deal dan

Levenson, 2016). 


\section{DAFTAR PUSTAKA}

Ali, H., \& Purwandi, L. (2017).Millennial Nusantara. Jakarta: PT Gramedia Pustaka Utama.

Alvi, A.K. \& Abbasi, A.S. (2012). Impact of organizational justice on employee engagement in banking sector of Pakistan. Middle-East Journal of Scientific Research, 12(5), 643-649

Asian Productivity Organization. (2017). APO productivity Databook. Tokyo: Asian Productivity Organization

Badan Pusat Statistik Provinsi DKI Jakarta. (2017). Jakarta Dalam Angka 2016. Jakarta: Badan Pusat Statistik Provinsi DKI Jakarta.

Badan Pusat Statistik. (2013). Proyeksi Penduduk Indonesia 2010-2035. Jakarta: Badan Pusat Statistik.

Biswas, S., Varma, A., \& Ramaswami. (2013). Linking distributive and procuderal justice to employee engagement through social exchange: A field study in India. International Journal of Human Resources Management, 24(8) , 1570-1587

Bass, B.M. \& Avolio, B.J. (1992) Developing trans-formational leadership: 1992 and Beyond. Journal of European Industrial Training, 14, 5.

Bertocci, D. (2009). Leader in organization there is a difference between leaders and manager. United States of America: University Press of America.

Bohlander, G., \& Snell, S. (2013). Principle of human resources management (16th International ed.).

South Western: Cengage Learning.

Colbert, E.M. (2012). The impact of leadership on employee engagement at achemical manufacturing company in the United States. (Doctoral Disertation) diakses dari : https://repository.upenn.edu/dissertations/AAI3537415/

Colquitt, J. (2001). On the dimensionality of organizational justice: A contruct validation of a measure. Journal of Applied Psychology, 86(3) .

Deal, J., \& Levenson, A. (2016). What millennials want from work: How to maximize engagement in today's workforce. United States of America: McGraw-Hill Education

Deloitte. (2016). The 2016 Deloitte Millennial Survey. United Kingdom: Deloitte. Diakses dari https://www2.deloitte.com/content/dam/Deloitte/global/Documents/About-Deloitte/gxmillenial-survey-2016-exec-summary.pdf

Devore, \& Peck. (1990). Statistic: A fresh approach (4th ed.). New York : McGraw-Hill International Education.

Espinoza, C., \& Ukleja, M. (2016). Managing the millennials: Discover the core competencies for managing today's force (2nd ed.). New Jersey: John Wiley \& Sons.

Ghosh, P., Rai, A., \& Sinha, A. (2014). Organizational justice and employee engagement: Exploring the linkage in public sector banks in India, Personnel Review, 43 (4). DOI: 10.1108/PR-08-2013-014 
Hess,James P., I.,II. (2012). Exploring the challenges of training and developing millennials in the business environment (Disertation)(Order No. 3497814). Available from ABI/INFORM Collection. (924410729). Retrieved

from https://search.proquest.com/docview/924410729?accountid=130508

Krejcie, R., \& Morgan, D. (1970). Determining sample size for research activites. Educational and Psychological Management, 30 , 607-618.

Kompas.com. (2017, December 9). Menaker Hanif: Produktivitas Tenaga Kerja Indonesia Terus Meningkat . Retrieved June 2018, from

Kompas.com: https://biz.kompas.com/read/2017/12/09/094833528/menaker-hanif-produktivitas-tenagakerja-indonesia-terus-meningkat

Lai, P., Lee, J., Lim, Y., Yeoh, R., \& Mohsin, F. (2015). The linkage between training and development and coworker support towards employee engagement in Hotel Industry. International Journal of Scienctific and Research Publication, 5 (5), V ISSN 2250-3153

Li, Y., Castano, G.,\& Li, Y. (2018). Linking Leadership styles to work engagement role of psychological capital among Chinese Knowledge Workers. Chinese Management Studies, 12(2), 433-452

Lubis, A.A. (2012). Analisis pengaruh gaya kepemimpinan terhadap employee engagement di PT XYZ. (Tesis). Diakses dari http://lib.ui.ac.id/file?file=digital/20333410-T32279Ade\%20Amalia\%20Lubis.pdf

Manuel, F.D.(2014). The effect of training \& development and employee engagement on perceived business performance (Master's Tesis) Diakses dari: "https://repository.up.ac.za/handle/2263/44214"

Murnianita, F.B. (2012). Pengaruh kepemimpinan terhadap employee engagement pada PT PLN (Persero Pusdiklat). (Tesis). Diakses dari http://lib.ui.ac.id/file?file=digital/20298791T30258\%20-\%20Pengaruh\%20kepemimpinan.pdf

Noe, R. (2017). Employee training and development (7th ed.). London: McGraw-Hill Education

Ozer, O., Ugurluoglu, O., Saygili, M. (2017). Effect of organizational justice on work engagement in healthcare sector of Turkey. Journal of Healthcare Management, 19(1) 1-11.

Robbins, S., \& Judge, T. (2015). Organizational Behaviour (16th). Edinburgh Gate: Pearson Education Limited.

Rothwell, W., \&et.al. (2014). Creating engaged employees it's worth the invesment. United States of America: American Society of Training and Development.

Rupp, D., \& Cropanzano, R. (2002). The mediating effects of social exhange relationship in predicting workplace outcomes from multifoci organizational justice. Organizational Behaviour and Human Decision Processes, 89, 925-946.

Saks, A. (2006). Antecedents and consequences of employee engagement. Journal of Managerial Psychology, 21(7), 600.

Saragih, E., Widodo, A., \& Prasetyo, B. (2016). Big city millennial workers in Indonesia and factors affecting their commitment to the organization. Pertanika Journal of Sciences and 
Humanities, 24 , 47-58.

Sattar, T., Ahmad, K., \& Hassan, S. (2015). Role of human resources practices in employee perfomances and job satisfaction with mediating effect of employee engagement. Pakistan Economic and Social Review, 53(1), 81-96.

Schaufeli, W. B., Salanova, M., Roma, V.G., \& Bakker, A.B. (2002) The measurement of engagement and burnout: A two sample confirmatory factor analytic approach. Journal of Happiness Studies, 3, p. 71-92

Schaufeli, W., Bakker, A., \& Salanova, M. (2006). The measurment of work engagement with short questionnaire across national study. Educational and Pschological Measurement, 66(4).

Surji, K. (2013). The negative effects and consequences of employee turnover and retention on the organization and its staff. European Journal of Business and Management, 5(25) .

Yulianti, P. (2016). Procedural justice, organizational trust, organizational identification, dan pengaruhnya pada employee engagement. Jurnal Manajemen Teori dan Terapan, 9(3)

Zemke, R., Raines, C., \&Filipczak, B. (2013). Generation at work: managing the clash of boomers, Gen Xers, and Gen Yers in the workplace (2nd ed.). New York: American Management Association

Zhang, T., Avery, G., Bergsteiner, H., \& More, E. (2014). The relationship between leadership paradigms and employee engagement . Journal of Global Responbility, 5(1) , 4-21. 